\title{
GENERALIZED METHOD OF DESIGNING UNMANNED REMOTELY OPERATED COMPLEXES BASED ON THE SYSTEM APPROACH
}

\author{
Volodymyr Blintsov \\ Department of electrical engineering of ship and robotic complexes \\ Admiral Makarov National University of Shipbuilding \\ 9 Heroiv Ukrainy ave., Mykolaiv, Ukraine, 54025 \\ volodymyr.blintsov@nuos.edu.ua \\ Olexandr Klochkov \\ Department of electrical engineering of ship and robotic complexes \\ Admiral Makarov National University of Shipbuilding \\ 9 Heroiv Ukrainy ave., Mykolaiv, Ukraine, 54025 \\ oleksandr.klochkov@nuos.edu.ua
}

\begin{abstract}
Self-propelled underwater systems belong to the effective means of marine robotics. The advantages of their use include the ability to perform underwater work in real time with high quality and without risk to the life of a human operator. At present, the design of such complexes is not formalized and is carried out separately for each of the components - a remotely operated vehicle, a tether-cable and cable winch, a cargo device and a control and energy device. As a result, the time spent on design increases and its quality decreases. The system approach to the design of remotely operated complexes ensures that the features of the interaction of the components of the complex are taken into account when performing its main operating modes. In this paper, the system interaction between the components of the complex is proposed to take into account in the form of decomposition of "underwater tasks (mission) - underwater technology of its implementation - underwater work on the selected technology - task for the executive mechanism of the complex" operations. With this approach, an information base is formed for the formation of a list of mechanisms of the complex, the technical appearance of its components is being formed, which is important for the early design stages. Operative, creative and engineering phases of the design of the complex are proposed. For each phase, a set of works has been formulated that cover all the components of the complex and use the author's existence equations for these components as a tool for system analysis of technical solutions.

The perspective of the scientific task of the creative phase to create accurate information models of the functioning of the components of the complex and models to support the adoption of design decisions based on a systematic approach is shown.

The obtained results form the theoretical basis for finding effective technical solutions in the early stages of designing remotely operated complexes and for automating the design with the assistance of modern applied computer research and design packages.
\end{abstract}

Keywords: remotely operated vehicles, system approach, design phase, equation of existence.

\section{Introduction}

A significant part of the search, inspection, environmental protection and other underwater work is traditionally performed with a wide involvement of remotely operated vehicles (ROV) [1, 2]. Such devices are used, as a rule, from the ship's carrier, on which the control and energy device (CED), cargo device (CD), cable winch (CW) with tether cable (TC) are located.

The main advantages of the ROV use in marine practice include performing work under the control or supervision of a human operator in real time. This ensures the high quality and performance of the ROV underwater mission, eliminates the risk to human life in comparison with traditional diving technologies [3].

A promising direction in the ROV development is the creation of unmanned remotely operating complexes (ROC) based on them, when they are equipped with CDs to fully automate the implementation of the underwater mission and is installed on unmanned carrier ships (CS).

The equipment composition of a typical ROC is shown in Fig. 1. 


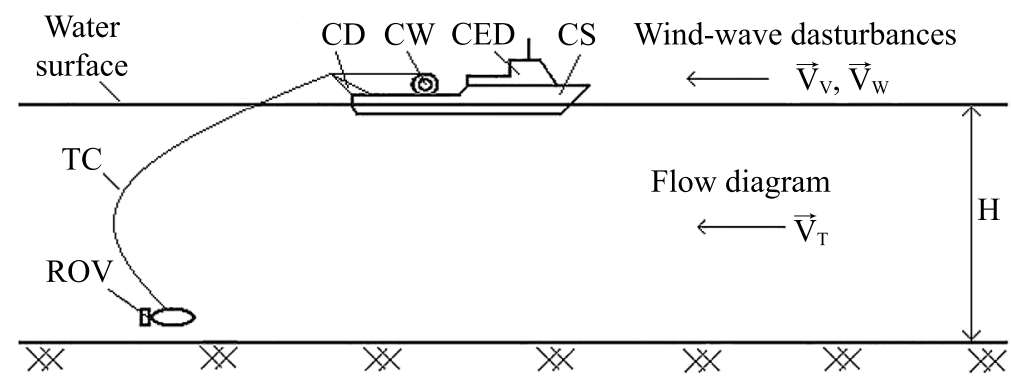

Fig. 1. Equipment composition of a typical ROC

At present, the design and creation of the ROC and ROV is mainly performed as a unique research and engineering activity based on the cognitive approach (that is, not formalized). This increases the duration of the design stage of the creation of such equipment and, ultimately, their cost.

A wide variety of ROV applications and the high relevance of the ROC creation stimulate the development of a generalized methodology for their design as a separate type of marine robotics, based on the achievements of system theory [4].

The main hypothesis of the article is the possibility and expediency of transferring the methodology for the design of the ROVs to the principles of a systems approach as the theoretical basis for automating the processes of their design in the early stages of development.

\section{Literature review and problem statement}

Modern methods of ROC design cover almost the full range of issues related to the creation of their main component ROVs themselves, their tether cables and control and energy device.

The first scientific papers on this issue were published in the $80 \mathrm{~s}$ of the last century and quite fundamentally formulated the design tasks of that period and the first technical solutions regarding the ROV and TC as unique oceanographic equipment [5-7].

In further studies, scientists focused on the development and improvement of ROV individual components (engines with electric and hydraulic drives [8], navigation and control systems $[9,10]$, buoyancy materials $[11])$, as well as on the creation of attachments and tools for the remote performance of underwater operations $[12,13]$.

Over the past 10 years, the ROV design has been further developed in the following areas:

- improvement of their manual and automated control systems;

- development of methods for creating cheap ROVs, including for shallow water;

- creation of training ROVs.

For example, in [14], a modular approach to the creation of hardware and software controls for ROV based on the open source platform Visor3 is described. This shortens the development time of the ROV software control systems and simplifies the implementation of their diagnostics and repair modes. The work [15] describes the use of the built-in operating system $\mu \mathrm{C} / \mathrm{OS}-\mathrm{II}$, which software gateway ensures the operation and stability of work in real time. The work [16] presents the constructions of controllers used to control the ROV depth control system, which involves the use of elements of artificial intelligence - a fuzzy logic controller SIFLC, an adaptive neuro-fuzzy inference system ANFIS), a controller of fuzzy logic Mamdani and a traditional controller based on the PID controller. The work [17] is devoted to the development of underwater video surveillance systems with the service function of scaling an underwater object.

Recently, in connection with the intensification of underwater operations in shallow water (depths of up to 50-100 meters), there has been a tendency to create cheap ROV, which had high operational properties, in particular, in terms of automation of control and information processing. For example, in [18], an easy-to-use, portable, safe, and reliable ROV is developed that is capable of performing scientific research under the guidance of students. University Teknologi Malaysia scientists have developed and built low cost ROV based on the use of cheap materials (polyvinyl chloride, etc.) [19]. In [20], the mechanical design, propulsion properties, electrical systems, as well as the software architecture of the graphical user interface for creating a shallow-purpose ROV are 
explained in detail. The work [21] is devoted to the design and development of low-cost miniature ROV for work at shallow depths with complex trajectories of movement.

In [22], a prototype ROV with three degrees of freedom is developed and tested, which is connected to the fuel and energy complex by unshielded twisted pairs of conductors, where a microcontroller is used to transfer data between the joystick and the ROV.

In addition to these areas, scientists are working on issues of an integrated approach to the ROV creation.

Thus, in [23], designs of naval ROV, which provide reliable visual information for the observation and maintenance of ship hulls and underwater structures of Columbia port equipment, are presented. The design is presented as a complex of four main subsystems: mechanical naval, computer hardware and software, navigation and control. The most responsible design solutions are evaluated taking into account environmental conditions, size limitations, hydrostatics, hydrodynamics, degrees of freedom, the availability of instruments and control equipment. The CAD-CAE and CFD (Computational Fluid Dynamics) computing tools are used as design and research tools.

Significant results are obtained in the direction of the practical creation and application of the ROV. For example, in [24], the design and creation of the ROV Ariana-I created at the University of Shiraz (IR Iran) is described. This system is equipped with sensors of rotation, pitch, roll and depth, which provide a sufficient number of feedback signals, giving the system six degrees of freedom. The video system is based on the Ethernet equipment, the control and feedback of the sensors are transmitted via the RS485 bus, and the video signal, the signaling of water flow and the battery charging wire on one multicore cable.

Research $[25,26]$ focuses on the ROV development, which use experimental data transmission systems through the acoustic channel, inertial sensors, numerical simulation in Matlab (Simulink), etc.

Research [27] presents the concept of the ROV design for the inspection of underwater oil and gas fields, in which the control of spatial motion is performed using vectorized propellers.

Important ROV variants are created for the inspection of underwater pipelines [28], for remote investigation of the underwater environment with the transmission of information via cable to the coast station [29].

A number of ROVs are designed and created for educational tasks, in particular, for preparing students of colleges and universities [30-33].

The most thorough studies in the areas of the ROV design and their control systems in recent years have been performed in [34-36]. Thus, the work [34] presents the ROV development and construction, which differ conceptually depending on their application - micro, mini, light, heavy classes of ROV, etc. The paper [35] addresses the issues of ROV and ROC classification, while the paper [36] proposes the concept of representing the ROC as a maritime object with flexible connections.

These and other scientific work in the direction of the ROC design are associated with the research of their individual components - ROV, TC, control systems and the like. However, the issue of creating a unified methodology for the ROC design in the composition of the ROV, TC, $\mathrm{CW}, \mathrm{CD}$ and CED as a marine complex, designed to function as a single system, is not covered in modern scientific literature. The urgency for the maritime practice of creating such complexes is due to the need to perform a wide range of underwater missions in automatic mode, including from the unmanned CS.

The creation of such complexes is a complex applied scientific task; therefore, their design should be carried out on the basis of a system approach.

The aim of research is development of a generalized ROC design methodology based on a systematic approach as a theoretical basis for finding technical solutions in the early stages of their design.

To achieve the aim it is proposed to solve the following tasks:

- to establish the features of the application of a systematic approach to the ROC design;

- to develop the substantive part of the design procedure for ROC, which implements the principles of the system approach. 


\section{The results of the development of a generalized methodology for the ROC design}

\section{1. Features of the application of a systematic approach to the ROC design}

The essence of the system approach $S$ to design a modern high-tech and market competitive product is considering the functioning of the components of the product, taking into account their interaction [37]. Such interaction between the ROC components (Fig. 1) should be analyzed in the following sequence of operations:

- underwater tasks $\mathrm{U}_{\mathrm{Z}}$, which should accomplish the ROC;

- underwater technology $U_{T}$, which should be implemented by the ROC to perform the task $U_{Z}$;

- a lot of underwater work $U_{J}$, which must be performed using this technology $U_{T}$;

- a lot of tasks $U_{V}$ for $Y_{\text {ROC }}$ actuators that implement the $U_{J}$.

Thus, there is the following sequence of operations of the designer-systems engineering for the ROC design:

$$
\mathrm{S}=\mathrm{U}_{\mathrm{Z}} \rightarrow \mathrm{U}_{\mathrm{T}} \rightarrow \mathrm{U}_{\mathrm{J}} \rightarrow \mathrm{U}_{\mathrm{F}}
$$

The set of tasks $U_{F}$ forms the information base for the formation of a list of $Y_{R O C}$ mechanisms and can be used to form the technical appearance of future ROC components - ROV, CW, $\mathrm{CD}, \mathrm{CED}$, as well as to form requirements for the TC operational properties.

The ROC design based on the principles of a systematic approach (analysis of the functioning of the ROC components, taking into account their interaction and taking into account the influence of the environment) can be represented by the following phases:

- formulation of the main factors of its future application $\mathrm{X}_{\mathrm{P}}$ (production phase, the final product of which is the development of technical requirements (technical specifications) $G$ to the future of the product;

- product design (creative phase, the end result of which $\mathrm{P}_{\mathrm{P}}$ is the overall structure and composition of product $\mathrm{K}$, its previous material $\mathrm{M}$, energy $\mathrm{E}$, informational I and operational $\mathrm{J}$ characteristics) [38];

- technical design of the product $\mathrm{C}_{\mathrm{P}}$ (the engineering phase, the end result of which is the technical design - a set of drawings and other technical documentation, in general, meet the technical requirements $G)$.

Thus, in the general case, from the standpoint of a systematic approach to the design of a modern high-tech and market competitive product, it is possible to present a variety of basic operations:

$$
\mathrm{S}=\left.\left\{\mathrm{X}_{\mathrm{P}} ; \mathrm{P}_{\mathrm{P}} ; \mathrm{C}_{\mathrm{P}}\right\}\right|_{\mathrm{G}}
$$

Let's consider these design phases in more detail.

\section{2. Development of the content part of the ROC design methodology}

In the case of ROC creation as a whole market product, the components of a systematic approach can be formulated as follows.

The formulation of the main factors of the ROC use $\mathrm{X}_{\mathrm{p}}$ (production phase - external design):

- definition and preliminary analysis of information about the basic underwater task $A=\left\{A_{1}, \ldots A_{N}\right\}$, which should be carried out by the ROC;

- determination of the characteristics of the aquatic environment $\mathrm{Z}$, in which the ROC should work (characteristics of the working area (depth $H$, wind $\vec{V}_{V}$ and wave $\vec{V}_{\mathrm{W}}$ disturbances, diagrams of the underwater flow $\vec{V}_{\mathrm{T}}$, hydrophysical $\mathrm{X}_{\mathrm{HF}}$ and hydrochemical $\mathrm{X}_{\mathrm{HC}}$ characteristics of the aquatic environment, etc.).

Thus, the staged phase of the ROC creation can be described by the following sets of design works:

$$
\mathrm{X}_{\mathrm{P}}=\{\mathrm{A} ; \mathrm{Z}\}
$$




$$
\begin{gathered}
\mathrm{A}=\left\{\mathrm{A}_{1}, \ldots \mathrm{A}_{\mathrm{N}}\right\} ; \\
Z=\left\{H ; \vec{V}_{V} ; \vec{V}_{W} ; \vec{V}_{\mathrm{T}} ; X_{H F} ; X_{H C}\right\},
\end{gathered}
$$

where $\mathrm{N}$ - the number of basic underwater tasks for the created ROC.

$R O C$ design $\mathrm{P}_{\mathrm{p}}$ (creative phase - internal design):

- definition and analysis of design constraints on the created $\mathrm{ROC} \mathrm{O}_{\mathrm{ROC}}$ - mass-dimensional $\mathrm{O}_{\mathrm{M}}$, energy $\mathrm{O}_{\mathrm{E}}$, information $\mathrm{O}_{\mathrm{I}}$, operational $\mathrm{O}_{\mathrm{J}}$, cost $\mathrm{O}_{\mathrm{Ek}}$;

- determination of preliminary information on the structure and composition of $\mathrm{K}_{\mathrm{ROC}}$ equipment of ROC components (underwater vehicle $\mathrm{K}_{\mathrm{ROV}}$, cable $\mathrm{K}_{\mathrm{TC}}$, cable winch $\mathrm{K}_{\mathrm{CW}}$, cargo device $\mathrm{K}_{\mathrm{CD}}$ and control and energy device $\mathrm{K}_{\mathrm{CED}}$ ), which are necessary for underwater tasks $\mathrm{A}$;

- substantiation of the ROV architectural-constructive type $\mathrm{Q}_{\mathrm{ROV}}$ as the central task of the creative phase - the hydrodynamic type of the ROV case, the arrangement of the propulsive-steering devices and the external replaceable tool, etc.;

- development of virtual 3D-models of VM ROC components $\left(\mathrm{VM}_{\mathrm{ROV}}, \mathrm{VM}_{\mathrm{TC}}, \mathrm{VM}_{\mathrm{CW}}\right.$, $\mathrm{VM}_{\mathrm{CED}}$ та $\left.\mathrm{VM}_{\mathrm{CD}}\right)$;

- development of mathematical models MM as an instrumental basis for the ROC analysis models of ROC operation in quasi-stationary and dynamic modes $\mathrm{MM}_{\mathrm{F}}$, necessary to verify the compliance of the complex being created with the technical requirements $\mathrm{G}$, and economic-mathematical models $\mathrm{MM}_{\mathrm{E}}$ (models of the cost of creating ROC with a certain structure and composition $\mathrm{K}$ ) to verify compliance with the requirements of value constraints $\mathrm{O}_{\mathrm{Ek}}$;

- a preliminary analysis of the possibility of ROC creation according to specified technical requirements $\mathrm{G}$ on the basis of solving the equations of the ROC existence $\mathrm{R}_{\mathrm{ROC}}$ [38] This analysis is performed by compiling and solving the equations of the material characteristics of the ROC components $\mathrm{R}_{\mathrm{M}}$ (ROC mass and volume balance equations, etc.), the energy balance equations of the ROC components $R_{E}$, the equations of their information support $R_{I}$, and the equations providing the ROC performance characteristics $\mathrm{R}_{\mathrm{J}}$; the numerical values of these equations are formed using data on the characteristics of the ROC components contained in the database DB of previously created ROV, TC, CW, CD and CED, as well as market-accessible nodes and systems of the specified equipment;

- in the case of a positive result of the preliminary analysis, the database of the component parts $\mathrm{DB}_{\mathrm{K}}$ and the construction materials $\mathrm{DB}_{\mathrm{M}}$ for the ROC components are generated, based on information from the DB;

- in the case of a negative result of the preliminary analysis, a search is made for solutions to adjust the structure and/or replace equipment $\mathrm{K}$ of ROC components or an order is created for designing and creating new equipment.

Thus, the implementation of a systems approach in the ROC design provides for the implementation of the following set of design works (creative phase):

$$
\begin{gathered}
\mathrm{P}_{\mathrm{P}}=\left\{\mathrm{O}_{\mathrm{ROC}} ; \mathrm{K} ; \mathrm{Q}_{\mathrm{ROV}} ; \mathrm{VM} ; \mathrm{MM} ; \mathrm{R}_{\mathrm{ROC}} ;\left.(\mathrm{M} ; \mathrm{E} ; \mathrm{I} ; \mathrm{J})\right|_{\mathrm{DB}}\right\} ; \\
\mathrm{O}_{\mathrm{ROC}}=\left\{\mathrm{O}_{\mathrm{M}} ; \mathrm{O}_{\mathrm{E}} ; \mathrm{O}_{\mathrm{I}} ; \mathrm{O}_{\mathrm{J}} ; \mathrm{O}_{\mathrm{Ek}}\right\} ; \\
\mathrm{K}_{\mathrm{ROC}}=\left\{\mathrm{K}_{\mathrm{ROV}} ; \mathrm{K}_{\mathrm{TC}} ; \mathrm{K}_{\mathrm{CW}} ; \mathrm{K}_{\mathrm{CED}} ; \mathrm{K}_{\mathrm{CD}}\right\} ; \\
\mathrm{VM}=\left\{\mathrm{VM}_{\mathrm{ROV}} ; \mathrm{VM}_{\mathrm{TC}} ; \mathrm{VM}_{\mathrm{CW}} ; \mathrm{VM}_{\mathrm{CED}} ; \mathrm{VM}_{\mathrm{CD}}\right\} ; \\
\mathrm{MM}=\left\{\left.\mathrm{MM}_{\mathrm{F}}\right|_{\mathrm{G}} ;\left.\mathrm{MM}_{\mathrm{E}}\right|_{\mathrm{O}_{\mathrm{E}}}\right\} ; \\
\mathrm{R}_{\mathrm{ROC}}=\left.\left\{\mathrm{R}_{\mathrm{M}} ; \mathrm{R}_{\mathrm{E}} ; \mathrm{R}_{\mathrm{I}} ; \mathrm{R}_{\mathrm{J}}\right\}\right|_{\mathrm{G}} ; \\
\mathrm{M}=\left.\left\{\mathrm{M}_{\mathrm{ROV}} ; \mathrm{M}_{\mathrm{TC}} ; \mathrm{M}_{\mathrm{CW}} ; \mathrm{M}_{\mathrm{CED}} ; \mathrm{M}_{\mathrm{CD}}\right\}\right|_{\mathrm{DB}} ;
\end{gathered}
$$




$$
\begin{gathered}
\mathrm{E}=\left.\left\{\mathrm{E}_{\mathrm{ROV}} ; \mathrm{E}_{\mathrm{TC}} ; \mathrm{E}_{\mathrm{CW}} ; \mathrm{E}_{\mathrm{CED}} ; \mathrm{E}_{\mathrm{CD}}\right\}\right|_{\mathrm{DB}} ; \\
\mathrm{I}=\left.\left\{\mathrm{I}_{\mathrm{ROV}} ; \mathrm{I}_{\mathrm{TC}} ; \mathrm{I}_{\mathrm{CW}} ; \mathrm{I}_{\mathrm{CED}} ; \mathrm{I}_{\mathrm{CD}}\right\}\right|_{\mathrm{DB}} ; \\
\mathrm{J}=\left.\left\{\mathrm{J}_{\mathrm{ROV}} ; \mathrm{J}_{\mathrm{TC}} ; \mathrm{J}_{\mathrm{CW}} ; \mathrm{J}_{\mathrm{CED}} ; \mathrm{J}_{\mathrm{CD}}\right\}\right|_{\mathrm{DB}} .
\end{gathered}
$$

Obviously, a promising scientific task of the creative phase is the automation of the ROC design processes based on the creation of accurate information models of their operation in specified modes $A$ and models to support the adoption of design decisions based on a systems approach.

ROC technical design $C_{\mathrm{p}}$ (engineering phase - internal design):

- execution of design calculations $\mathrm{B}_{\mathrm{ROC}}$, confirming the performance and reliability of the ROC components, confirming compliance with the technical requirements of $\mathrm{G}$ to it and the implementation of design constraints $\mathrm{O}_{\text {ROC }}$ on its creation;

- development of project documentation (drawings) $\mathrm{D}_{\mathrm{ROC}}$, necessary for the manufacture of new components and systems for ROC components;

- development of documentation $\mathrm{D}_{\mathrm{M}}$ and $\mathrm{D}_{\mathrm{K}}$ for the purchase, respectively, of materials and ROC components and systems, which are included in the project from the databases $\mathrm{DB}_{\mathrm{M}}$ and $\mathrm{DB}_{\mathrm{K}}$;

- development of documentation on the preliminary feasibility study for the ROC creation $\mathrm{D}_{\mathrm{TEO}}$.

Thus, the implementation of a systems approach in the ROC technical design provides for the implementation of the following set of design and engineering works (engineering phase):

$$
\begin{gathered}
\mathrm{C}_{\mathrm{P}}=\left\{\mathrm{B}_{\mathrm{ROC}} ; \mathrm{D}_{\mathrm{ROC}} ; \mathrm{DB}_{\mathrm{M}} ; \mathrm{DB}_{\mathrm{K}} ; \mathrm{D}_{\mathrm{TEO}}\right\} \\
\mathrm{B}_{\mathrm{ROC}}=\left.\left\{\mathrm{B}_{\mathrm{ROV}} ; \mathrm{B}_{\mathrm{TC}} ; \mathrm{B}_{\mathrm{TW}} ; \mathrm{B}_{\mathrm{CED}} ; \mathrm{B}_{\mathrm{CD}}\right\}\right|_{\mathrm{G}, \mathrm{O}_{\mathrm{ROC}}} \\
\mathrm{D}_{\mathrm{ROC}}=\left.\left\{\mathrm{D}_{\mathrm{ROV}} ; \mathrm{D}_{\mathrm{TC}} ; \mathrm{D}_{\mathrm{CW}} ; \mathrm{D}_{\mathrm{CED}} ; \mathrm{D}_{\mathrm{CD}}\right\}\right|_{\mathrm{BD}} ; \\
\mathrm{D}_{\mathrm{M}}=\left.\left\{\mathrm{D}_{\mathrm{MROV}} ; \mathrm{D}_{\mathrm{MTC}} ; \mathrm{D}_{\mathrm{MCW}} ; \mathrm{D}_{\mathrm{MCED}} ; \mathrm{D}_{\mathrm{MCD}}\right\}\right|_{\mathrm{BD}} ; \\
\mathrm{D}_{\mathrm{K}}=\left.\left\{\mathrm{D}_{\mathrm{KROV}} ; \mathrm{D}_{\mathrm{KTC}} ; \mathrm{D}_{\mathrm{KCW}} ; \mathrm{D}_{\mathrm{KCED}} ; \mathrm{D}_{\mathrm{KCD}}\right\}\right|_{\mathrm{BD}} ;
\end{gathered}
$$

The relation (1)-(20) form the basis of the methodology of ROC design based on the system approach methodology. The formed list of design works of the production phase and design and construction phases of the ROC can be easily formalized by mathematical and computer modeling methods, makes it possible to involve modern CAD/CAM/CAE software packages in design, and CFD packages to study their operation.

\section{Discussion of the generalized methodology for ROC design}

ROCs form a large class of underwater robotics facilities. The significant advantages of their use include the ability to remotely perform underwater work in real time and without risk to the life of a human operator. Modern methods of designing such complexes are poorly systematized and relate to the design of their individual components - remotely operated vehicles, their tether cables and control systems. This increases the duration of the design work and reduces their quality.

Unmanned technologies for the implementation of underwater work require a systematic approach to the process of ROC design, which involves taking into account the peculiarities of the interaction of the components of the complex when performing its main operating modes. This allows to create complexes, the individual components of which are designed from a unified position of system engineers and most fully correspond to the ROC underwater missions.

It is proposed to implement a systematic approach to the ROC design in the form of decomposition of the offshore operation as "underwater tasks (mission) - underwater technology of its implementation - underwater work using the selected technology - a task for the executive mechanism of the complex" chain. This creates an information base for the formation of the list of 
executive mechanisms of the complex and forms the technical appearance of its components in the early stages of design.

The proposed production, creative, and engineering phases of the ROC design allow to clearly formulate the set of works that cover the design of all components of the complex. An important component of the creative design phase is the use of the developed system of existence of equations of the existence of the system, which allow to systematically evaluate design solutions for material, energy, information and operational characteristics. This allows already in the early stages of design to establish the possibility of ROC creation with specified characteristics.

Obtained for each phase of the set of design works include, in particular, the development of mathematical and virtual 3D-models of the ROC components. This allows to further transfer the design of such complexes on a fully computer technology using modern application software packages.

\section{Conclusions}

Modern approaches to the ROC and ROV design cover the study of their individual components - ROV, TC and control systems. Approaches to the design of these components as elements of a single automatic underwater complex are not covered in the literature.

The expediency is shown and features of application of the system approach to the unmanned ROC design are established. A system interaction between the components of the complex has been proposed to take into account both the decomposition of "underwater tasks (mission) - underwater technology of its implementation - underwater work according to the chosen technology - the task for the executive mechanism of the complex" operations.

It is proposed to perform the ROC design as a sequential implementation of the staging, creative and engineering phases. For each phase, a number of papers were formulated that cover all the components of the complex (ROV, TC, CW, CD and CED) and use the existence equations for these components as a tool for system analysis of technical solutions.

A promising scientific task of the creative phase is the automation of the ROC design processes based on the creation of accurate information models of their operation in specified modes A and models to support the adoption of design decisions based on a systems approach.

The obtained results form the theoretical basis for finding effective technical solutions in the early stages of ROC design and for automating the design with the involvement of modern applied $\mathrm{CAD} / \mathrm{CAM} / \mathrm{CAE}$ applications and CFD packages.

\section{References}

[1] Milne, P. H. (1980). Underwater Engineering Surveys. Gulf Publishing Company, 366.

[2] Yastrebov, V. S., Sobolev, G. P., Smirnov, A. V. et. al. (1981). Sistemy i elementy glubokovodnoy tekhniki podvodnyh issledovaniy. Leningrad: Sudostroenie, 304.

[3] Button, R. W., Kamp, J., Curtin. T. B., Dryden, J. (2009). Unmanned Undersea Vehicles. RAND Corporation, 220.

[4] Luhmann, N. (2012). Introduction to Systems Theory. Polity, 300.

[5] Smrcina, K. L., Fish, J. P. (1989). Remotely Operated Vehicle. Reliability Study. Phase II Final Report. Arlington, 124. Available at: https://apps.dtic.mil/dtic/tr/fulltext/u2/a240672.pdf

[6] Yastrebov, V. S., Gorlov, A. A., Siminskiy, V. V. (1986). Elektroenergeticheskie ustanovki podvodnyh apparatov. Leningrad: Sudostroenie, 208.

[7] Last, G., Williams, P. (1991). An introduction to ROV operations. Oilfield Publications Ltd, 232.

[8] Templeton, J. S. (2006). Offshore Technology in Civil Engineering: Hall of Fame Papers from the Early Years. American Society of Civil Engineers, 160.

[9] Jacak, W. (1999). Intelligent robotic Systems: design, planning, and control. International Federation for Systems Research International Series on Systems Science and Engineering. Vol. 14. Kluwer Academic Publishers, 310.

[10] Triantafyllou, M. S., Hover, F. S. (2003). Maneuvering and Control of Marine Vehicles. Massachusetts, 145. 
[11] Molloy, P. (2000). Smart Materials for Subsea Buoyancy Control. Glasgow Theses Service, 369.

[12] Gianluca, A. (2006). Underwater Robots. Motion and Force Control of Vehicle-Manipulator Systems. Springer, 268. doi: http://doi.org/10.1007/11540199

[13] Shostak, V. P. (2011). Podvodnye apparaty-roboty i ih manipulyatory. Moscow: GEOS, 134.

[14] Aristizábal, L. M., Rúa, S., Gaviria, C. E., Osorio, S. P., Zuluaga, C. A., Posada, N. L., Vásquez, R. E. (2016). Design of an open source-based control platform for an underwater remotely operated vehicle. DYNA, 83 (195), 198-205. doi: http://doi.org/10.15446/dyna.v83n195.49828

[15] Liu, W. D., Li, X. Y., Gao, L. (2012). Design of a Gateway for Remotely Underwater Vehicles. Applied Mechanics and Materials, 209-211, 2138-2141. doi: http://doi.org/10.4028/www.scientific.net/ amm.209-211.2138

[16] Azmi, M. W. N., Aras, M. S. M., Zambri, M. K. M., Harun, M. H. (2018). Comparison of Controllers Design Performance for Underwater Remotely Operated Vehicle (ROV) Depth Control. International Journal of Engineering \& Technology, 7, 419-423.

[17] Girgin, S. (2013). A Design Project of a Remotelyoperated Underwater Vehicle. Izmir.

[18] Guerra, J., Heinevetter, R., Tristan, M., Killian, P., Waschura, A. (2014). Proteus: Mini underwater remotely operated vehicle. Santa Clara University, 115. Available at: https://www.researchgate.net/ publication/274698477_Proteus_Mini_Underwater_Remotely_Operated_Vehicle_ROV_Mechanical_Engineering Thesis

[19] Ahmed, Y. M., Yaakob, O., Sun, B. K. (2014). Design of a New Low Cost ROV Vehicle. Jurnal Teknologi, 69 (7). doi: http://doi.org/10.11113/jt.v69.3262

[20] Anwar, I., Mohsin, M. O., Iqbal, S., Abideen, Z. U., Rehman, A. U., Ahmed, N. (2016). Design and fabrication of an underwater remotely operated vehicle (Single thruster configuration). 2016 13th International Bhurban Conference on Applied Sciences and Technology (IBCAST). doi: http://doi.org/10.1109/ ibcast.2016.7429932

[21] Nguyen, D. A., Cao, Q. H., Nguyen, P. H. (2016). Research, Design and Control of a Remotely Operated Underwater Vehicle. 5-th World Conference on Applied Sciences, Engineering \& Technology. Available at: https://pdfs.semanticscholar.org/0974/e8a5b7460ee4009cac1f772b0a66ab3726d4.pdf

[22] Wiryadinata, R., Nurliany, A. S., Muttakin, I., Firmansyah, T. (2017). Design of a Low Cost Remotely Operated Vehicle with 3 DoF Navigation. Bulletin of Electrical Engineering and Informatics, 6 (1), 13-23. Available at: https://media.neliti.com/media/publications/61851-EN-design-of-a-low-cost-remotlyoperated-ve.pdf

[23] Ramírez, J. A., Vásquez, R. E., Gutiérrez, L. B., Flórez, D. A. (2007). Mechanical/Naval Design of an Underwater Remotely Operated Vehicle (ROV) for Surveillance and Inspection of Port Facilities. Volume 16: Transportation Systems. doi: http://doi.org/10.1115/imece2007-41706

[24] Marzbanrad, A., Sharafi, J., Eghtesad, M., Kamali, R. (2011). Design, Construction and Control of a Remotely Operated Vehicle (ROV). Volume 7: Dynamic Systems and Control; Mechatronics and Intelligent Machines, Parts A and B. doi: http://doi.org/10.1115/imece2011-65645

[25] Wang, Y.-L., Lu, C.-Y. (2012). Design and parameter estimation of a remotely operated underwater vehicle. Design and parameter estimation of a remotely operated underwater vehicle. Journal of Marine Engineering \& Technology, 11 (2), 39-48. Available at: https://www.tandfonline.com/doi/pdf/10.1080/20464 177.2012.11020265? need Access $=$ true

[26] García-Valdovinos, L. G., Salgado-Jiménez, T., Bandala-Sánchez, M., Nava-Balanzar, L., Hernández-Alvarado, R., Cruz-Ledesma, J. A. (2014). Modelling, Design and Robust Control of a Remotely Operated Underwater Vehicle. International Journal of Advanced Robotic Systems, 11 (1). doi: http://doi.org/10.5772/56810

[27] Vasantharaj, R., Paravastu, V., Shobana, M., Loganayaki, S. (2014). Remotely Piloted Unmanned Underwater Vehicle Design and Control for Pipeline Maintenance. Proceedings of National Conference on Man Machine Interaction, 40-43.

[28] Joochim, C., Phadungthin, R., Srikitsuwan, S. (2015). Design and development of a Remotely Operated Underwater Vehicle. 2015 16th International Conference on Research and Education in Mechatronics (REM). doi: http://doi.org/10.1109/rem.2015.7380385

[29] Rahimuddin, Hasan, H., Rivai, H. A., Iskandar, Y., Claudio, P. (2018). Design of Omni Directional Remotely Operated Vehicle (ROV). Journal of Physics: Conference Series, 962, 012017. doi: http://doi.org/ 10.1088/1742-6596/962/1/012017 
[30] Lien, B. (2009). Design Your Own Underwater Remotely Operated Vehicle (ROV). Technology Teacher, 68 (7), 22-25. Available at: https://eric.ed.gov/?id=EJ838392

[31] ROV PROGRAM - TEAM MANUAL. Underwater Robotics for High School Students (2010). Eastern Edge Robotics, 63. Available at: https://www.marinetech.org/files/marine/files/Curriculum/ Other\%20Curriculum\%20Resources/MIROV2MANUAL.pdf

[32] Harsh, S., Vignesh, P. (2013). Design, Fabrication \& Testing of Underwater Remotely Operated Vehicle. LAP Lambert Academic Publishing, 72. Available at: https:/www.amazon.in/FabricationTesting-Underwater-Remotely-Operated/dp/3659314099

[33] Bernier, M., Foley, R. T., Rioux, P., Stech, A. (2010). Latis II Underwater Remotely Operated Vehicle Technical Report. The University of MAINE, 20. Available at: http://www.mickpeterson.org/ Classes/Design/2009_10/Projects/Website-ROV-Amy/UMaine\%20ROV\%20Final\%20Report.pdf

[34] Roslan, I. S., Muhamad Said, M. F., Abu Bakar, S.A. (2015). Conceptual Design of Remotely Operated Underwater Vehicle. Journal of Transport System Engineering, 1 (2), 15-19.

[35] Certification and Classification of Unmanned Submersibles. Unmanned Submersibles (ROV, AUV) and Underwater Working Machines (2009). Germanishcer Lloyd.

[36] Dudykevych, V., Oleksandr, B. (2016). Tasks statement for modern automatic control theory of underwater complexes with flexible tethers. EUREKA: Physics and Engineering, 5, 25-36. doi: https://doi.org/ $10.21303 / 2461-4262.2016 .00158$

[37] Blanchard, B. S., Fabrycky, W. J. (2006). Systems Engineering and Analysis. Prentice Hall International Series in Industrial \& Systems Engineering. Upper Saddle River: Pearson Prentice Hall, 804.

[38] Blintsov, V., Klochkov, O. (2016). Equations of existence selfpropelled underwater system as assessment of the possibility of its creation. Pidvodni tekhnolohiyi, 3, 25-30. 